\title{
Über die Wirkung des Alkohols auf den Kreislauf des Menschen und der Tiere.
}

\author{
Von \\ Hiroshi Takahashi. \\ (高 橋 寬) \\ (Aus dem pharmakologischen Institut von Prof. S. Yagi, \\ an der Tohoku Universitüt zu Sendai.)
}

\section{Einleitung}

Dass alkoholische Getränke bei akuten Kreislaufstörungen oft prompt eklatanten Erfolg bringen, ist durch klinische Erfahrungen von altersher bestätigt. Diese günstige Wirkung rührt offenbar von dem in diesen Getränken enthaltenen Alkohol her, und darüber, auf welche Weise er den Kreislauf günstig beeinflusst, haben zwar bisher viele Autoren Untersuchungen angestellt, aber ihre Resultate und ihre Deutung weichen sehr voneinander ab, sodass die in Rede stehende Frage noch als fast ganz offen anzusehen ist. Worauf dies beruht, ist unklar, dürfte aber daher kommen, dass viele Forscher, ohne sich um das Wie der klinischen Anwendungsmethode und des Einflusses auf den Kreislauf zu bekümmern, diese Frage einfach tierexperimentell lösen wollten. Will man die Wirkung des Alkohols auf den Kreislauf des Menschen durch das Tierexperiment erkennen, so muss man zuerst genau untersuchen, welchen Einfluss der Weingeist im grossen und ganzen auf den menschlichen Kreislauf ausübt, ferner festellen, ob er auf Versuchstiere ganz gleich wirkt ; sonst sind die Resultate der Analyse ganz bedeutungslos. Deshalb will ich zuerst die Alkoholwirkung bei Menschen und dann tierexperimentell untersuchen.

\section{Versuche an Menschen.}

Mitteilungen von Untersuchungen über den Einfluss des Alkohols und alkoholischer Getränke auf Blutdruck und Pulsfrequenz liegen in nicht geringer Anzalıl vor. Von ihnen sind die hauptsächlichsten 
folgende: Weissenfeld ${ }^{1}$ fand bei einem Menschen, welchem er 50$70 \mathrm{ccm}$ Xereswein mit einem Alkoholgehalt von 15,3\% per os gegeben hatte, mit den Baschschen Sphygmomanometer deutliche Blutdruck-

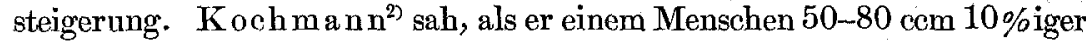
Alkohollösung oder $40 \mathrm{ccm}$ Portwein mit einem Alkoholgehalt von $18 \%$ innerlich verabreichte, nach ca. 10 Minuten regelmässigen Blutdruckanstieg, welcher in ca. 30 Minuten seinen Höhepunkt erreichte und in maximo $30 \mathrm{~mm}$. Hg betrug und ca. 1 Stunde nachher verschwand. Nach ihm soll dieser erhöhte Blutdruck die Folge der Überkompensierung der dureh Alkohol bewirkten peripheren Vasodilatation dureh Kontraktion der Eingeweidegefässe sein. Der Puls wird, wenn sich die Versuchsperson rubig hält, in seiner Frequenz nicht wesentlich, aber in seiner Qualität immer verändert; er wird zugleich mit der Blutdrucksteigerung in der Amplitude höher und katadikrotisch, was dadurch zustande kommen soll, dass trotz der Erweiterung der peripheren Gefässe der Blutdruck in die Höhe geht. Bachem $m^{3)}$ hat durch Selbstversuch erfahren, dass beim Einnehmen einer kleinen Menge (entsprechend 20-50 ccm Alkohol absolutus) alkoholischer Getränke in 2-3 Minuten der Blutdruck anzusteigen beginnt, während $\mathrm{John}^{4}$ nachgewiesen hat, dass bei Verabreichung 3-6\%iger Alkohollösung in grosser Menge anfangs nur selten Blutdruckanstieg, meistens zuerst Sinken des diastolischen Druckes bei gleichbleibenden oder nur wenig ansteigendem systolischen Druck hervorgerufen wird, nachher letzterer erniedrigt und die Pulsfrequenz, anch wenn die Versuchsperson ruhig bleibt, deutlich vermehrt wird. Lie $b^{5 j}$ sagt, dass die Untersuchung an gesunden oder erkrankten Menschen ergeben hat, dass verdünnter Whisky in kleiner Menge, z. B. 5-10 ccm, gar keine Veränderungen bewirkt, wäbrend konzentrierter sowobl bei Gesunden als auch bei Erkrankten zuweilen (in 8 unter 14 Fällen) den systolischen und diastolischen Druck in leichtem Grade steigert, aber bei einer grossen Dosis vielmehr beide herabsetzt. Trotzdem also die einen nachgewiesen haben, dass eine kleine Menge Alkohol regelmässig deutlich blutdrucksteigernd wirkt, sagen die anderen, dass sie einen Blutdruckanstieg leichten Grades bewirkt, und wieder andere, dass sie fast immer blutdruckherab-

1) Weissenfeld, zit. nach Kochmann, Heffter's Handbuch der experimentellen Pharmakologie, I, Berlin 1923, 322.

2) Kochmann, Arch. internat. de Pharm. et de Thérap., 1905, 15, 443.

3) B a chen, Areh. f. ges. Physiol., 1906, 114, 508.

4) Jo h n, Zeitschr. f. exp. Path. u. Therap., 1908, 5, 579.

5) Li eb, Journ. of Americ. Med. Assoc., 1915, 64, 989. 
setzend wirkt. Aber im grossen und ganzen scheint es keinem Zweifel zu unterliegen, dass Alkohol in geringer Menge den Blutdruck erhöht. Nur über die Pulszahl sind die Ansichten der Autoren nicht einig; während einige von ihnen behaupten, dass keine Veränderungen hervorgerufen werden, sagen die anderen, dass eine deutliche Vermehrung nachweisbar ist.

Ich will nun also den Einfluss einer kleinen Menge Alkohol auf Blutdruck und Pulsfrequenż zugleich untersuchen. Da nach obigen Mitteilungen der Einfluss des Weingeistes auf den Kreislauf bei Gesunden und bei Erkrankten nicht sehr verschieden zu sein scheint, wählte ich als meine Versuchspersonen 20-50-jährige Männer aus. Ich liess sie 3 Stunden nach dem Mittagessen in einem bestimmten Versuchszimmer auf dem Bette ruhig in Rückenlage liegen und in der darauf folgenden 1 Stunde beobachtete ich an ihnen ab und zu den Blutdruck und die Pulsfrequenz, dann gab ich ihnen Alkohol, um den Einfluss des letzteren auf die beiden ersteren zu untersuchen. Zur Blutdruckmessung gebrauchte ich das von Recklinghausen modifizierte Sphygmomanometer nach Riva-Rocci und verwendete die auskultatorische Methode nach Korotkow, da die Manipulation dabei einfach ist und dadurch ein relativ genaues Resultat gewonnen wird. Der Weingeist wurde bald als $10 \%$ ige, bald als 50\%ige wässerige Lösung, bald als Rotwein (ca. 10\% Alkohol enthaltend), bald als Branntwein (ca. 50\% Alkohol enthaltend) per os gegeben. Die unter diesen Bedingungen angestellten Versuche ergaben, dass die Wirkung des Alkohols auf die Zirkulation zwar von der Menge abhängt, aber nicht von der Art der Getränke. Also werden hier nur die Konzentrationen des Alkohols angegeben, aber nicht besonders die Art der Getränke.

Gibt man einem Abstinenten $10 \mathrm{ccm}$ 50\%iger Alkohollösung innerlich, so werden systolischer und diastolischer Druck erhöht, aber die Pulszahl meistens anfangs vermindert, nur selten vermehrt, der Blutdruck sofort rasch nach der Verabreichung gesteigert, dann allmählich erniedrigt, um 20-30 Minuten danach auf die normale Höhe zurückzugehen. Die Pulszahl vermindert sich im grossen und ganzen mit der Hebung des Blutdruckes und geht mit dessen Restitution auf die Norm zurück. Fig. 1 veranschaulicht einen deutlichen Fall dieses Verhaltens.

Schon 2 Minuten nach stomachaler Verabreichung von $10 \mathrm{ccm}$ 50\%iger Alkohollösung wurde der systolische Druck um $8 \mathrm{~mm} \mathrm{Hg}$ und der diastolische um $5 \mathrm{~mm} \mathrm{Hg}$ gehoben, die Pulszahl um 3 pro Min. vermindert. Nach 10 Minuten war ersterer noch um $3 \mathrm{~mm}$ $\mathrm{Hg}$ und letzterer noch um $2 \mathrm{~mm} \mathrm{Hg}$ höher als im Anfange und die Pulsfrequenz gleich der vor der Verabreichung. Nach 30 Minuten waren der systolische und der diastolische Druck und die Pulsfrequenz fast gleich wie vor der Verabreichung. 


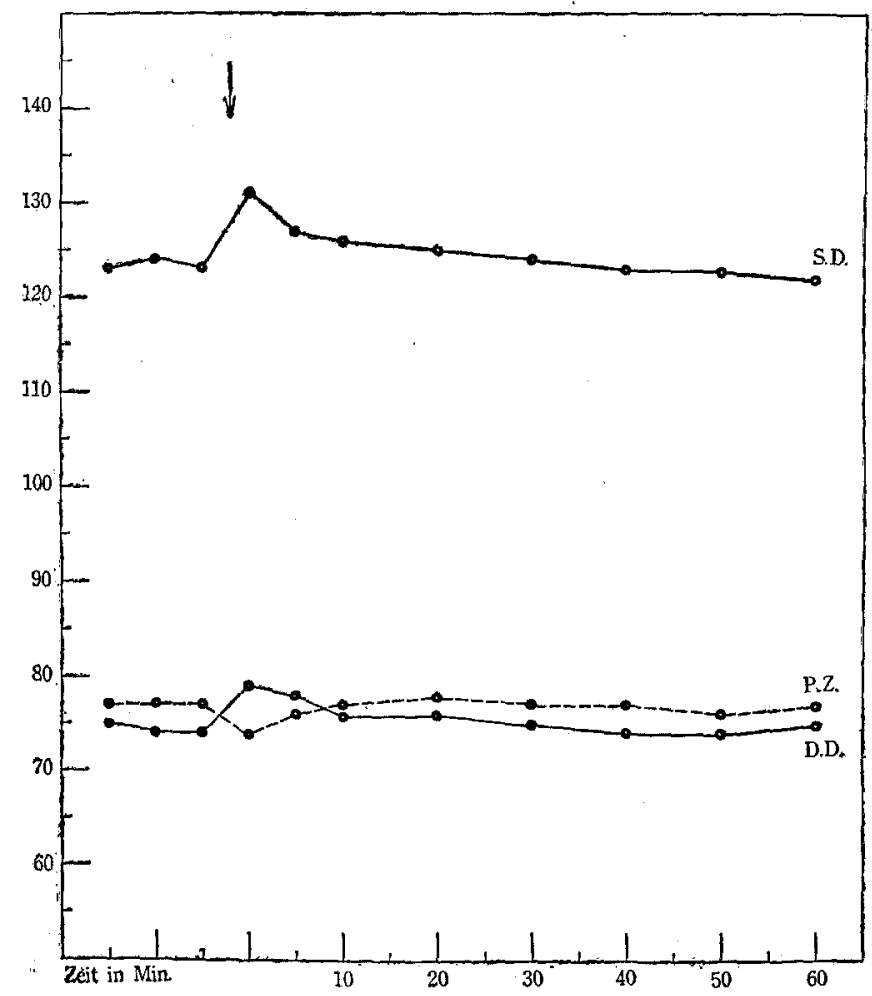

Fig. 1.

35 jähriger Abstinenzler. $10 \mathrm{ccm} 50 \%$ iger Alkohollösung innerlich. S.D. $=$ Systolischer Druck (in mm $\mathbf{H g}$ ); D.D. $=$ Diastolischer Druck (in $\mathrm{mm} \mathrm{Hg}$ ); P.Z. = Pulszahl.

Gibt man z. B. eine relativ grosse Menge Alkohol in derselben Konzentration, z. B. $50 \mathrm{ccm}$, so werden dieselben Veränderungen hervorgerufen, aber es stellen sich in 10-20 Minuten deutliche Gesichtsrötung und beginnende Senkung des systolischen und diastolischen Druckes ein. Der erniedrigte Druck erreicht in 40-50 Minuten sein Maximum und geht dann sehr allmählich in die Höhe, um nach ca. 2 Stunden fast normal hoch zu werden. Die Pulszahl nimmt mit der Herabsetzung des Blutdruckes zu und mit seiner Steigerung ab. Diese Veränderungen waren zwar graduell verschieden, aber in allen 10 Experimenten nachweisbar. Fig. 2 gibt ein deutliches Beispiel dafür. 


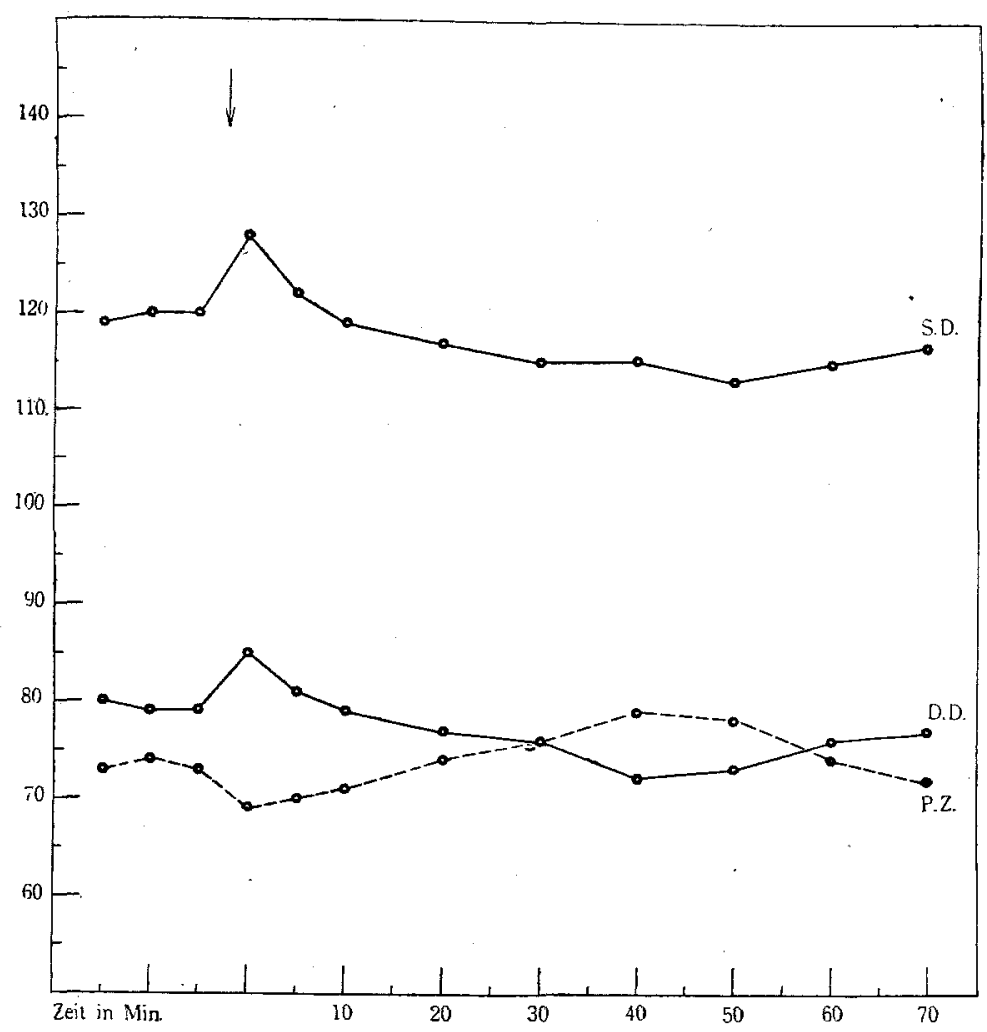

Fig. 2 .

38 jühriger Abstinenzler. $50 \mathrm{ccm}$ 50\%iger Alkohollösung innerlich. S.D. $=$ Systolischer Druck $($ in $\mathrm{mm} \mathrm{Hg}) ;$ D.D. $=$ Diastolischer Druck (in $\mathrm{mm} \mathrm{Hg}$ ); P.Z. = Pulszahl.

Der Fall bekam $50 \mathrm{ccm}$ 50\%iger Alkohollösung stomachal, bald danach wurde der systolische resp. der diastolische Druck um $8 \mathrm{~mm} \mathrm{Hg}$ resp. $6 \mathrm{~mm}$ gesteigert und die Pulszahl un 4 pro Min. vermindert. Nach 30 Minuten zeigte ersterer resp. letzterer eine $\mathbf{E r}$ niedrigung von 5 resp. $4 \mathrm{~mm} \mathrm{Hg}$ und die Pulsfrequenz eine Abnahme von 2, und nach 40 Minuten war jener resp. dieser gleich dem nach 30 Minuten resp. um noch $4 \mathrm{~mm}$ niedriger und die Pulszahl um 4 vermehrt, im Vergleich zum Anfang.

Die registrative Untersuchung der Pulswellen in diesen Fällen mittelst des Jaquet schen Sphygmographs ergab, dass der Puls bei anfänglicher Abnahme kleiner und gespannter wurde und undeutliche Rückstosselevation zeigte, während er gegen die Zeit seiner Zunahme grösser und weicher wurde und deutliche Rückstosselevation aufwies. Fig. 3 stellt ein Bei- 


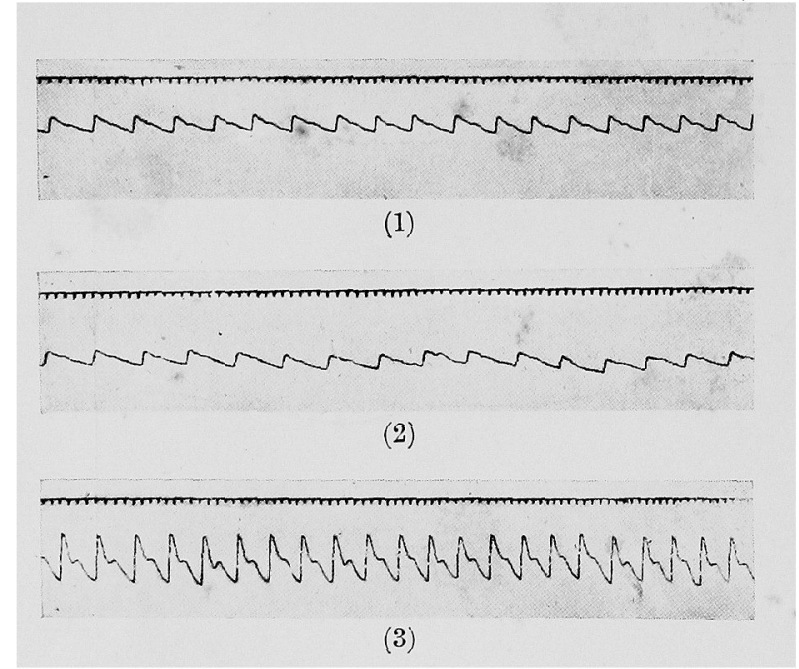

Fig. 3.

38 jïhriger Abstinenzler, $50 \mathrm{ccm}$ 50\% iger Alkohollösung innerlich.

(1) Vor Alkohol; Pulszahl 68 pro Min.

(2) 2 Min. nach Alkohol; Pulszahl 62 pro Min.

(3) 30 Min. nach Alkohol; Pulszahl 77 pro Min. spiel dar, bei welchem solche Veränderungen auftraten. Diese Veränderungen kommen manchmal auch in der Norm vor, aber nicht regelmässig. Sie waren in 5 von den $10 \mathrm{Fällen} \mathrm{fast}$ gar nicht zu erkennen und auch in den übrigen 5 , in welchen sie sich zeigten, nur sehr schwach.

Doch in den Fällen, denen ich innerlich 10\%ige Alkohollösung gegeben habe, ist das Verhalten etwas anders. Gibt man nämlich Absti-

nenten $10 \mathrm{ccm}$ davon, stellen sich meistens keine Veränderungen ein. In 3 von den 10 Fällen waren sie nach Verabreichung nur eine vorübergehende Blutdrucksteigerung leichten Grades zu finden. Werden aber 50 oder $250 \mathrm{ccm}$ gleich konzentrierten Weingeistes gegeben, so zeigt sich bisweilen im ersten Stadium ein temporärer Blutdruckanstieg leichten Grades, meistens aber keine Veränderungen, jedoch inmer nach 10-20 Minuten beginnende Senkung des systolischen und des diastolischen Druckes, welche allmählich deutlicher wird und nach ca. 40-50 Minuten ihr Maximum erreicht, dann allmählich verschwindet, um in ca. 2 Stunden auf die Norm zurückzugehen. Die Senkung ist graduell umso deutlicher, je grösser die absolute Menge des Alkohols ist. Die Pulsfrequenz verändert sich im ersten Stadium nicht, beschleunigt sich aber vor und nach dem Blutdruckanstieg und nimmt umso mehr zu, je deutlicher letzterer wird, und dann mit dessen Restitution wieder ab bis sie schliesslich normal wird. Dieselben Veränderungen, aber weit schwächer, treten auch bei den an Alkohol Gewöhnten auf. Ein typisches Beispiel für letztere veranschaulicht Fig. 4. 


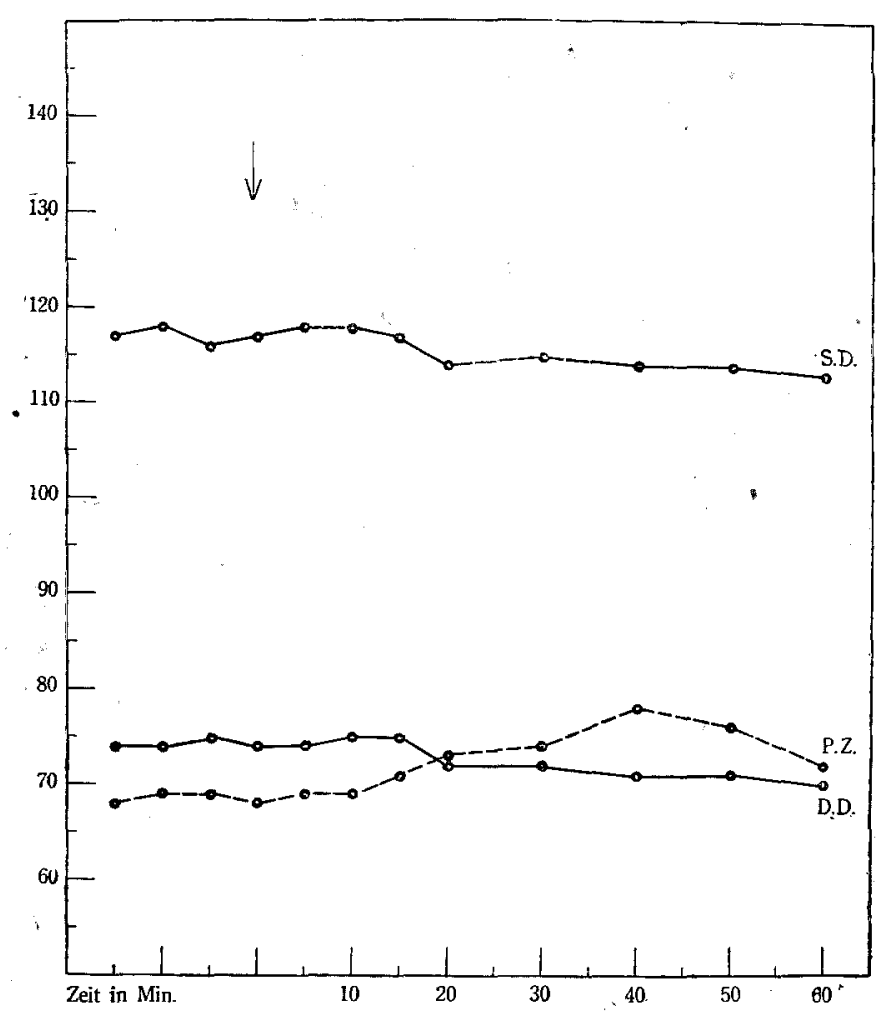

Fig. 4.

40 jühriger Abstinenzler. $250 \mathrm{ccm}$ 10\% iger Alkohollösung innerlich. S.D. $=$ Systolischer Druck (in mm Hg); D.D. = Diastolischer Druck (in $\mathrm{mm} \mathrm{Hg}$ ); P.Z. $=$ Pulszahl.

Bei stomachaler Darreichung ron $250 \mathrm{ccm}$ 10\%iger Alkohollösung weisen sowohl systolischer als auch diastolischer Druck eine Erhöhung von $1 \mathrm{~mm} \mathrm{Hg}$ und die Pulszahl pro Min. eine Zunahme von 1 auf, nach 30 Minuten wurden die beiden ersteren um $3 \mathrm{~mm}$ $\mathrm{Hg}$ niedriger und letztere um 6 höher als vor der Verabreichung, und nach 40 Minuten zeigte sich beim systolischen und diastolischen Druck ein weiterer Abstieg von $1 \mathrm{~mm} \mathrm{Hg}$ und bei der Pulszahl eine weitere Zunahme von 4 und nach 60 Minuten bei ersteren eine Senkung von $50 \mathrm{~mm} \mathrm{Hg}$ und bei letzterer eine Zunahme von 4, im Vergleich mit dem Zustand vor der Verabreichung.

Nach obigen Versuchsergebnissen ist es sicher,'dass bei innerlicher Darreichung von Alkohol Blutdruck und Pulsfrequenz verändert werden. Diese Veränderungen sind im allgemeinen bei den an Alkohol Gewöhnten nicht regelmässig und nicht deutlich, während sie bei den Abstinenten 
Regelmässigkeit und Deutlichkeit aufweisen. Wird nämlich Weingeist gegeben, so stellen sich vorïbergehende Blntdruckzunahme und Pulsfrequenzabnahme ein, welche graduell nicht sehr von dessen absoluter Menge vielmehr von seiner Konzentration abhängig sind; denn beide treten immer bei Verabreichung von 50\%igem Alkohol auf. Jedoch ist ihre Stärke nicht sehr verschieden, ob nun von letzterem $10 \mathrm{ccm}$ oder 50 ccm gegeben werden, ja auch bei Darreichung von $50 \mathrm{ccm}$ oder $250 \mathrm{ccm}$ 10\% igen Alkohols treten obige Veränderungen selten auf und sind dann auch nur leichten Grades. Dann wird der Blutdruck allmählich herabgesetzt und der Puls beschleunigt, was aber von der absoluten Menge des Alkohols abhängt und nicht sehr von dessen Konzentration, denn die oben erwähnten Veränderungen treten fast gar nicht auf, wenn man auch $10 \mathrm{ccm} 50 \%$ iger Alkohollösung gibt, aber sie zeigen sich bei Verabreichung von $250 \mathrm{ccm} 10 \%$ iger in derselben Stärke, als wenn man $50 \mathrm{ccm} 50 \%$ iger gegeben hätte. Danach muss man bei der Untersuchung des Einflusses des Alkohols auf Blutdruck und Pulsfrequenz auf die Konzentration und absolute Menge des Weingeistes und darauf, ob die Versuchsperson ein Abstinenter oder Gewöhnter ist, achten. Die Feststellung der Blutdrucksteigerung von $\mathrm{Weissenfeld^{1) }}$ und $\mathrm{Bache} \mathrm{m}^{3)}$ rührt wohl von der Verwendung konzentrierter Lösung her, bei John, ${ }^{-1)}$ der fast gar keinen Blutdruckanstieg gefunden hat, wohl vom Gebrauch einer verdünnten. Dass Lieb $b^{5}$ trotz Anwendung einer konzentrierten Lösung in gewissen Fällen Blutdrucksteigerung gesehen hat, dürfte das nicht darauf zurückzuführen sein, dass er zwischen Abstinenten und Gewöhnten keinen Unterschied gemacht hat? Wie dem auch sei, bei der Blutdruckerhöhung tritt diese gleich nach der Verabreichung und zwar gewöhnlich in leichtem Grade auf. Aber Kochmann kam zu einem anderen Resultate; angeblich fand er, der Blutdruck beginne nach 10 Minuten anzusteigen und sei auf dem Höhepunkt um $30 \mathrm{~mm} \mathrm{Hg}$ in die Höhe gegangen. Worauf dieser Unterschied beruht, ist nicht zu verstehen. Die Pulsfrequenz nimmt, wenn sich die Versuchsperson ruhig hält, bei Darreichung einer konzentrierten Lösung zuerst meistens ab, wenn diese aber, in einer grossen Menge gegeben wird, allmählich zu. Dass John Pulsvermehrung konstatiert hat, rührt wohl ebenfalls von der Darreichung einer verdünnten Iösung in grosser Menge her. Koch mann sagt, dass der Puls keỉne wesentlichen Veränderungen erfährt, was aber mit einem seiner Ergebnisse nicht übereinstimmt, nach welchem bei einer von ihm gegebenen Dosis in der Regel deutliche Pulszunahme erfolgt. Nach seinem Versuche soll der Puls beim Blutdruckanstieg grösser und katadikrotisch werden. 
Kann in der Tat solche Erscheinung auftreten?

Wie oben erwähnt, werden Blutdruckerhöhung und Pulsabnahme bei Anwendung einer konzentrierten Lösung deutlich hervorgerufen und zwar sofort nach der Verabreichung. Danach scheint wohl der Alkohol die sensiblen Nerven der Schleimhaut des Verdauungskanals zu reizen und dadurch reflektorisch die oben geschilderten Veränderungen zustande zu bringen. Versuchsweise habe ich einem Abstinenten Weingeist in den Mund gegeben und so dessen Einfluss auf Blutdruck und Pulsfrequenz untersucht und zwar auf folgende Weise: Nachdem ich festgestellt hatte, dass leichtes Gurgeln mit Wasser auf Blutdruck und Pulsfrequenz keinen nachweisbaren Einfluss ausübt, liess ich kurze Zeit mit 50\%iger Alkohollösung gurgeln, dann diese ausspeien und untersuchte den Einfluss auf

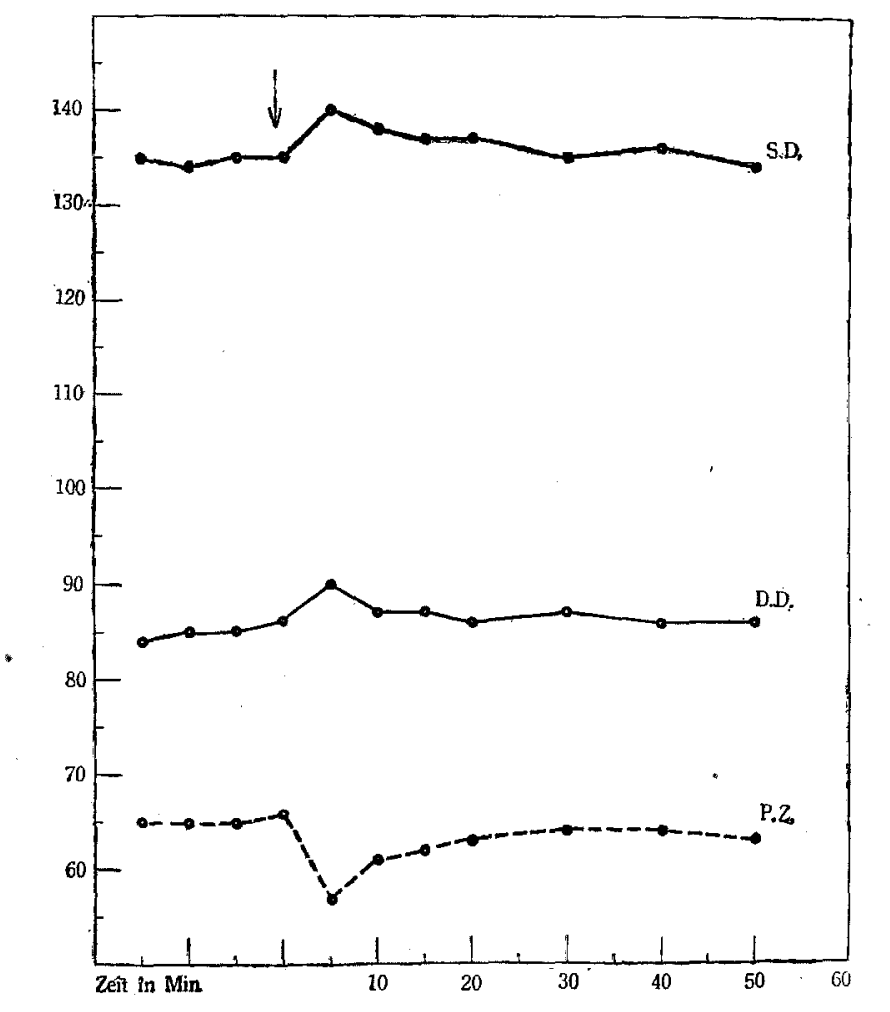

Fig. 5.

45 jähriger Abstinenzler. Gurgeln mit 50\%iger Alkohollösung. S.D. =Systolischer Druck (in mm Hg); D.D.=Diastolischer Druck (in $\mathbf{m m ~} \mathrm{Hg}$ ); P.Z. = Polszahl. 
den Blutdruck, wobei sich ergab, dass dieser bis zu 8 unter 10 Fällen sofort eine Zunahme aufwies (wenn sie auch schwächer war als bei stomachaler Zuführung einer gleich konzentrierten Lösung und zwar auch bei ein und derselben Versuchsperson). Dabei wird meistens die Pulszahl vermindert, aber bisweilen auch gar nicht oder sogar etwas vermehrt. Fig. 5 zeigt ein deutliches Beispiel dafür.

Gleich nach dem Gurgeln mit 50\%iger Alkohollösung zeigten systolischer und diastolischer Druck einen Anstieg von $5 \mathrm{~mm} \mathrm{Hg}$ und die Pulszahl pro Min. eine Abnahme von 8, danach allmählichen Rïckgang und nach 30 Minuten die beiden ersteren und letztere beinahe normalen Zustand.

Aus dem Erwähnten erhellt, dass die vorübergehende Blutdrucksteigerung und Pulsabnahme beim Einnehmen von Alkohol wenigstens zum Teil durch sensible Reizung der Mund- und Rachenschleimhaut reflektorisch bewirkt werden. Dass sie im allgemeinen schwächer sind als bei stomachaler Einführung, rührt wohl davon her, dass in diesem Falle die von der Rachen-, Ösophagus- und Magenschleimhaut stammende Wirkung fehlt. Dass Blutdruckanstieg die Pulsabnahme begleitet, wird nicht durch gesteigerte Arbeitsleistung des Herzens, sondern vielleicht durch Gefässverengernng infolge vasomotorischer Zentren bedingt; auch die verminderte Pulsfrequenz ist wohl gleichfalls die Folge der Erregung des Vaguszentrums, an welcher sich wohl auch die Zunahme des Blutdrucks beteiligt. Dagegen beruhen dessen Senkung und die Vermehrung der Pulsfrequenc, da sie von der absoluten Menge des Weingeistes abhängen und allmählich hervorgerufen werden, höchst wahrscheinlich auf der resorptiven Wirkung des letzteren. Da Blutdruckabnahme und Pulszunahme immer Schritt miteinander halten, so liesse sich denken dass letztere durch Nachlassen des Vagustonus als Folge ersterer entstehen könnte, oder es wäre auch möglich, dass beide unabhängig von einander auftreten. Aus obigen Resultaten kann man schliessen, dass konzentrierte alkoholische Getränke in kleiner Menge sofort den Blutdruck steigern, und dass wohl auf diese Wirkung die rasch auftretenden günstigen Erfolge bei akuter Herzschwäche zurückzuführen sind, dass aber Getränke, in grosser Menge verabreicht, weil sie blutdruckerniedrigend wirken, zwar auf die Krampfzustände der Gefässe günstig, jedoch auf Herzschwäche im Gegenteil schädlich wirken.

\section{Versuche an Kaninchen.}

1. Einfluss des Alkohols auf den normalen Kreislauf. Durch Versuche an Menschen wurde fèstgestellt, dass Gurgeln mit 
konzentrierten alkoholischen Getränken oder 50\%iger Alkohollösung oder stomachale Verabreichung beider sofort blutdrucksteigernd und pulsvermindernd wirkt, und wenn die absolute Menge des Alkohols gross ist, der Blutdruck ab- und die Pulsfrequenz zunimmt. Aber die Frage, auf welche Weise der Alkohol diese Veränderungen hervorruft, ist noch nicht gelöst. Ob tatsächlich Tiere auf Alkohol in ganz derselben Weise reagieren oder nicht, das ist noch unklar. Beim Auftreten der gleichen Reaktion kann man meines Erachtens aus den Wirkungen des Alkohols aufs 'Tier auf die beim Menschen schliessen. Zu den Experimenten wurden ca. 2 Kilogramm schwere Kaninchen gebraucht. Die Tiere wurden schwach mit Urethan narkotisiert, eventuell kurarisiert (unter künstlicher Atmung), dann in Rückenlage fixiert, die Carotis mit einem $\mathrm{Hg}$-Manometer verbunden und die Veränderungen des Blutdruckes und der Pulszabl auf einem rotierenden Papier registriert. Nun ist es selbstverständlich, dass eine Substanz wie Alkohol, welcher den Proteinstoff denaturiert und auf den betreffenden Ort reizend wirkt, Tieren verabreicht, je nach den verschiedenen Applikationsmethoden verschiedene Wirkungen zeigt. Doch haben viele Forscher darauf keine Rücksicht genommen, sondern nach beliebigen Applikationsverfahren Versuche angestellt, die dadurch gewonnenen Resultate sämtlich als Alkoholwirkungen angesehen und sind deshalb dazu gekommen, unmittelbare Schlüsse über die therapeutische Wirkung des Weingeistes daraus zu ziehen. Hat die Nichtübereinstimmung der Behauptungen der Forscher vielleicht darin ihren Grund? Deshalb habe ich nach verschiedenen Applikationsmethoden Alkohol gegeben, um das Verfahren der therapeutischen Wirkung zu analysieren und zugleich die nicht im Einklang miteinander stehenden Behauptungen der Autoren aufzuklären.

\section{a. Applikation auf die Mundschleimhaut.}

Zuerst soll untersucht werden, ob beim Bepinseln der Mundschleimhaut von Kaninchen mit Alkohollösung Blutdruck und Pulszahl dieselben Veränderungen erfahren wie bei der Versuchsperson, die ich mit konzentrierten alkoholischen Getränken gurgeln liess. Zu diesem Zwecke habe ich, indem ich einem Kaninchen unter schwacher Urethannarkose auf die Mundschleimhaut verschieden stark konzentrierte Alkohollösungen applizierte, Untersuchungen angestellt, die Folgendes ergaben : Durch 5\%ige und 10\%ige Lösung erleiden Blutdruck und Pulsfrequenz keine nachweisbaren Veränderungen, durch $20 \%$ ige und 30\%ige wird zuweilen und durch $40 \%$ ige und $50 \%$ ige in vielen Fällen ersterer gesteigert und 
letztere vermindert. $\mathrm{Ab}$ und $z u$ sinkt jener bevor er ansteigt. Der eben erwähnte Blutdruckanstieg beginnt sofort nach der Bepinselung, erreicht innerhalb 5 Minuten sein Maximum, nimmt dann allmählich ab, bis er in 10-20 Minuten fast auf die Norm zurückgeht. Fig. 6 veranschaulicht das deutlich.

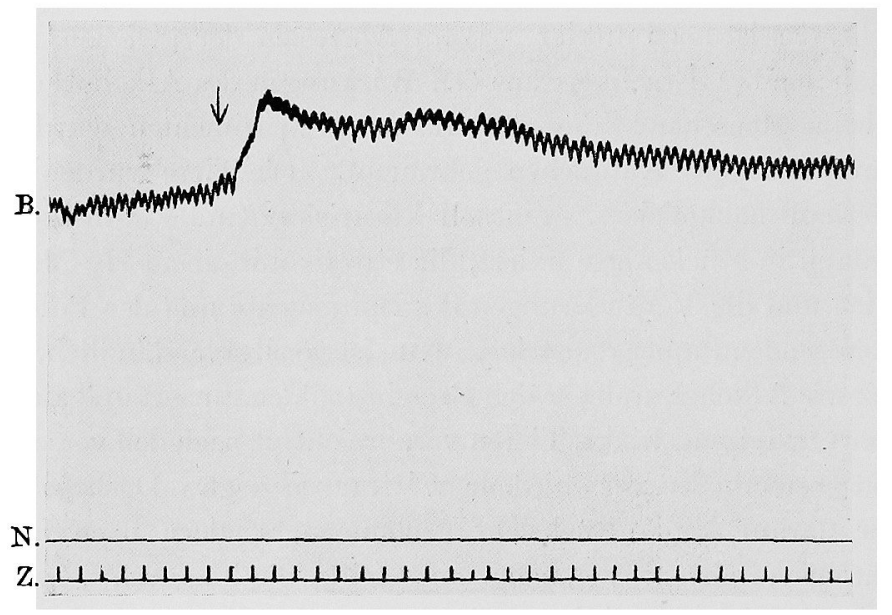

Fig. 6.

Kaninchen $2,2 \mathrm{~kg}$. Urethannarkose.

Bepinselung der Mundschleimhaut mit 50\%iger Alkohollösung.

B. $=$ Blutdruck; N. =Nulllinie; Z. =Zeit in 5 Sek.

Einige Minuten nach der Bepinselung mit 50\%iger Alkohollösung zeigte der Blutdruck, welcher vorher $104 \mathrm{~mm} \mathrm{Hg}$ betragen batte, $138 \mathrm{~mm} \mathrm{Hg}$, also eine Erhöhung um $34 \mathrm{~mm} \mathrm{Hg}$.

Die Pulszahl nahm mit der Steigerung des Blutdruckes ab und mit seiner Senkung zu, bis sie zur Norm zurück kam. Fig. 7 zeigt einen Beispiel davon.

Vor der Applikation betrug der Blutdruck $82 \mathrm{~mm} \mathrm{Hg}$ und die Pulszahl 264, pro Min. gleich nach der Bepinselung stieg ersterer auf $114 \mathrm{~mm}$. $\mathrm{Hg}$ und letztere sank auf 228 ; nach 5 Minuten zeigte jener $92 \mathrm{~mm} \mathrm{Hg}$ und diese 258.

Diese Resultate stehen mit denen, welche bei den Versuchen an Menschen gewonnen wurden, gut im Einklang, woraus klar hervorgeht, dass sie bei Mensch und Tier nicht wesentlich verschieden sind. Zuweilen steht unmittelbar nach der Applikation die Atmung ganz vorübergehend still, einige Zeit danach kommt sie in der Regel zur Beschleunigung. Sonst stellen sich keine unruhigen Zustände ein. Um festzustellen ob die oben erwähnten Kreislaufveränderungen durch Variation dieser Respira- 


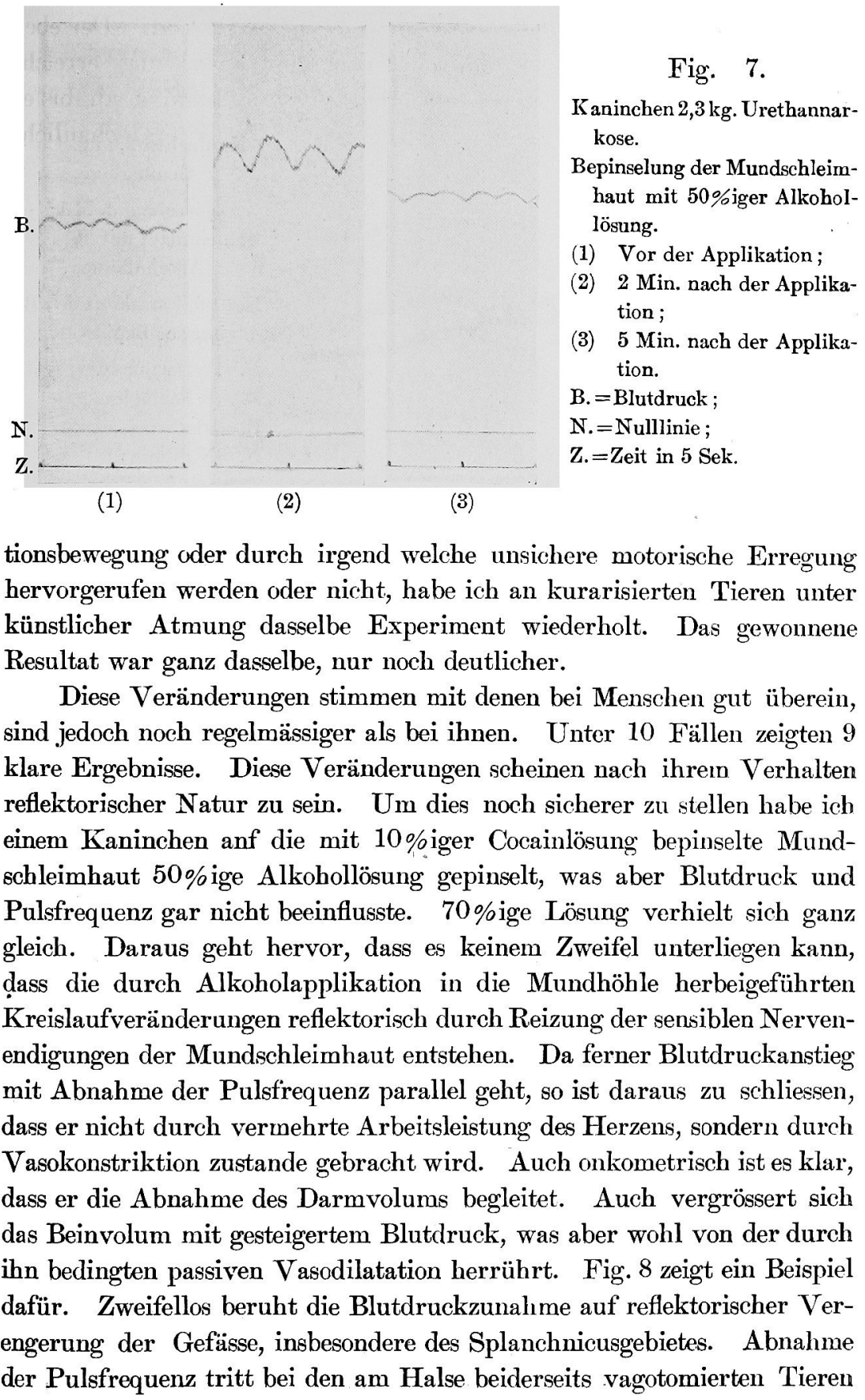




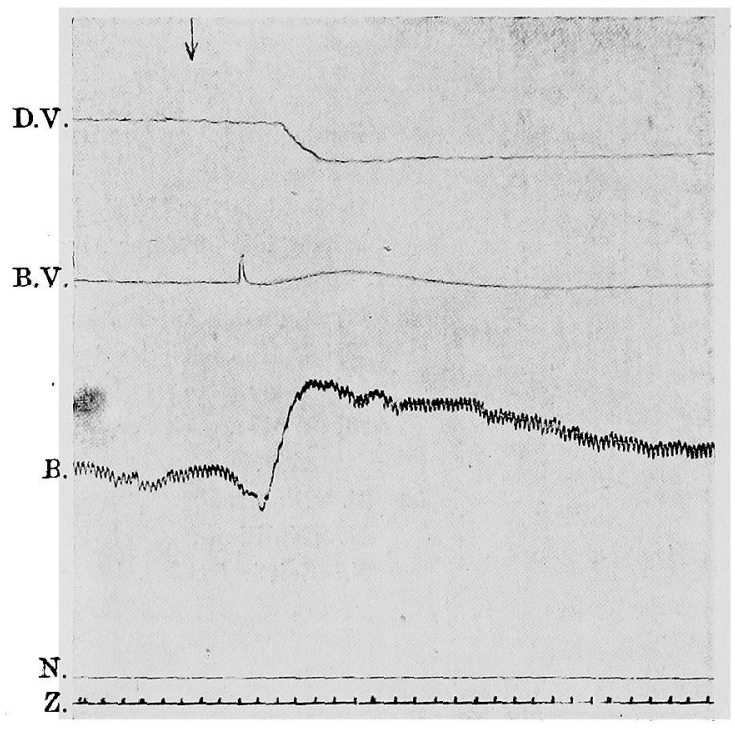

Fig. 8 .

Kaninchen 2,0 kg. Urethannarkose.

Bepinselung d. Mundschleimhaut mit 50\%iger Alkohollösung.

Der Pfeil markiert den Beginn der Bepinselung.

D.V. $=$ Darmvolum ;

B.V. = Beinvolum;

B. $=$ Blutdruck ;

$\mathrm{N} .=$ Nulllinie

Z. $=$ Zeit in 5 Sek.

nicht ein, also ist sie Folge der Erregung des Vaguszentrums. Aber ob das Zentrum reflektorisch gereizt wird oder durch die von der Blutdrucksteigerung herrührende Erregung, darüber eine Entscheidung zu fällen ist uumöglich.

\section{b. Stomachale Applikation.}

Die Mitteilungen über Untersuchungen, bei denen Tieren Alkohol stomachal gegeben wurde, sind ziemlich zahlreich. Nach den Resultaten von $\mathrm{Zimmerberg,}{ }^{67}$ Gutnikow, ${ }^{77}$ Rosenfeld, ${ }^{87}$ Brooks, $^{97}$ Lieb ${ }^{57}$ u.a. an Hunden und Kaninchen scheint Weingeist in kleiner Menge gar keine Wirkung auf den Blutdruck und die Pulsfrequenz auszuüben, in relativ grosser Dosis immer Erniedrigung des ersteren und Abnahme der letzteren, zuweilen im Beginn auch Blutdruckanstieg leichten Grades herbeizuführen. Auch nach den Versuchen von $\mathrm{Kuno}^{10)}$ an Kaninchen und Hunden erniedrigt Alkohol den Blutdruck, aber er wirkt auf die Pulsfrequenz bei Kaninchen und Hunden verschieden. Er fand bei ersteren keine erhebliche Veränderung oder eine Verminderung und bei letzteren Senkung des

6) Zimmerberg, zit. nach Kochmann, Heffter's Handbuch d. exp. Pharm. I, Berlin 1923, 317.

7) Gutnikow, Zeitschr. f. klin. Med,, 1892, 2l, 168.

8) Rosenfeld, zit. nach Loeb, Arch. f. exp. Path. u. Pharm., 1905, 52, 459.

9) Brooks, Journ. of Americ. Med. Assoc., 1910, 55, 372.

10) K u no, Kioto-Igaku-Zasshi, 1911, 8, 54 (jap.). 
Blutdruckes und Zunahme der Pulszahl. Ganz verschieden von diesen Resultaten sind die Resulate von Dixon. ${ }^{11}$ Er gab einem Hunde stomachal $60 \mathrm{ccm} 50 \%$ igen Alkohols und sah, wie dadurch der Blutdruck in die Höhe ging und das Beinvolum vorübergehend sich vergrösserte, um sich dann zu verkleinern.

Da bei der Applikation des Alkohols auf die Mundschleimhaut, wie schon im vorigen Kapitel erwähnt, der Blutdruck reflektorisch beeinflusst wird, so muss man bei stomachaler Einverleibung des Alkohols sein Eindringen in Form von Dampf oder Tropfen in die Mundhöhle vermeiden. Deshalb habe ich die Sonde, die in den Magen eingeführt werden sollte, mit einem $30 \mathrm{~cm}$ langen Gummischlauch verbunden, um von einem möglichst weit vom Munde entfernten Orte aus den Alkohol einführen zu können. Die Resultate der Experimente sind folgende: Gibt man schwach mit Urethan narkotisierten oder kurarisierten Kaninchen eine grosse Menge 50\%iger Alkohollösung, d. h. $10 \mathrm{ccm}$ pro kg Körpergewicht stomachal, so sinkt wenn auch nicht regelmässig, der Blutdruck sofort, das wurde nur in 2 unter 5 Fällen beobachtet. Fig. 9 zeigt ein Beispiel für. Unabhängig davon, ob sich vorläufige Blutdrucksenkung zeigt oder nicht, beginnt in allen Fällen 7-8 Minuten nach Verabreichung des AlkoholsallmählicheBlutdrucksenkung, welche im Verlauf der Zeit deutlicher wird und nach 30 Minuten fast die Hälfte des Anfangs-

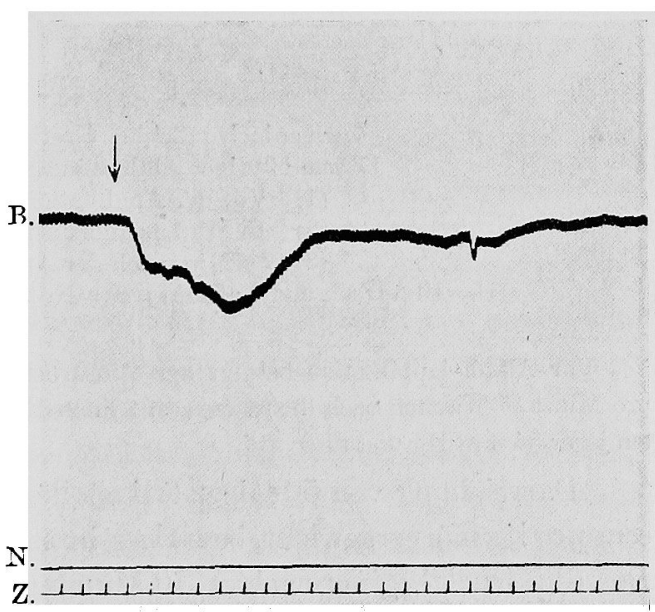

Fig. 9. Kaninchen 1,7 kg. Urethannarkose. $17 \mathrm{ccm} 50 \%$ iger Alkohollösung in den Magen. Der Pfeil markiert den Beginn der Applikation. B. = Blutdruck; N. = Nulllinie; Z. = Zejt in 5 Sek. drucks beträgt und nach langem Verweilen in diesem Zustande sehr allmählich zur Norm zurückkehrt. Die Pulszahl nimmt beim ersten geringsten Abstieg des Blutdruckes zu, aber bei dessen erheblicher Senkung im Gegenteil ab. Fig.

11) Dixon, Journ. of Physiol., 1906-1907, 35, 372. 
10 veranschanlicht das.

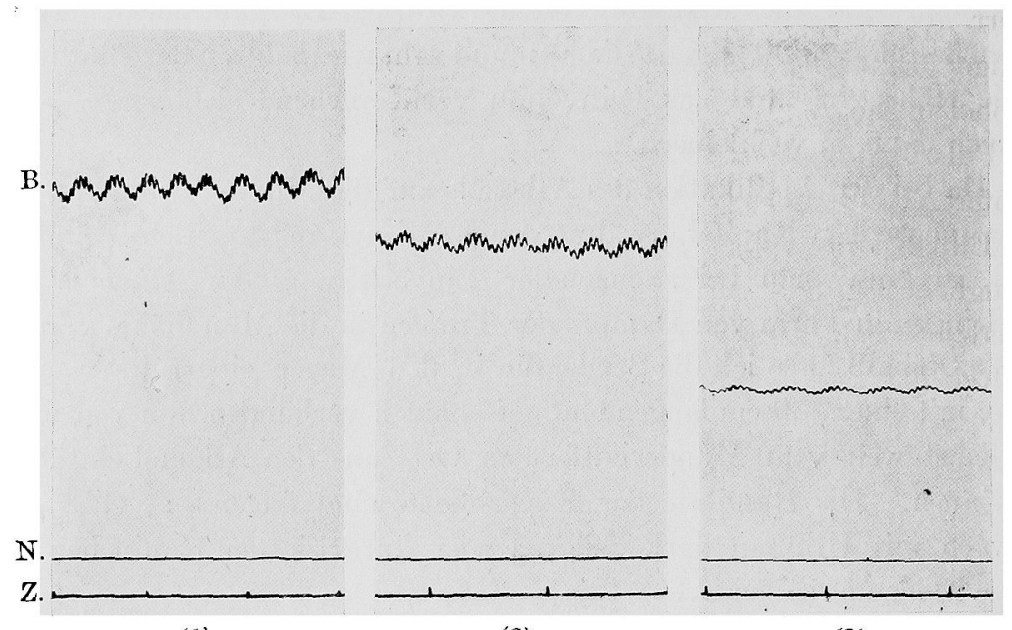

(1)

(2)

(3)

Fig. 10.

Kaninchen 2,4 kg. Urethannarkose.

$17 \mathrm{ccm} 50 \%$ iger Alkhollösung in den Magen.

(1) Vor der Applikation;

(2) 15 Min. nach der Applikation;

(3) $30 \mathrm{Min}$. nach der Applikation.

B. $=$ Blutdruck und Pulszahl ; N. $=$ Nulllinie; Z. = Zeit in 5 Sek.

Vor Alkoholapplikation beträgt der Blutdruck $104 \mathrm{~mm} \mathrm{Hg}$ und die Pulszahl 224 pro Min.; 15 Minuten nach ihr ist ersterer $98 \mathrm{~mm} \mathrm{Hg}$ und letztere 244 und nach 30 Minuten jener $54 \mathrm{~mm} \mathrm{Hg}$ und diese 216.

Darreichung von 50\%iger Alkohollösung in kleiner Menge, z. B. 4 ccm pro kg Körpergewicht, bewirkt sehr selten sofortigen Blutdruckabfall. Der Blutdruck beginnt nach ca. 10 Minuten zu sinken, wird in 30 Minuten am niedrigsten und nach 1 Stunde wieder fast normal. Die Pulszahl vermindert sich mit der Erniedrigung des Blutdruckes und kehrt allmählich mit der Erhöung des Blutdruckes zur Norm zurück.

Falls von einer verdünnten Alkohollösung, z.B. einer 10\% igen pro $\mathrm{kg}$ Körpergewicht, $20 \mathrm{ecm}$ oder $50 \mathrm{ccm}$ gegeben werden, so ändern sich Blutdruck und Pulszahl, wie bei der Verabreichung von 4 oder $10 \mathrm{ccm}$ einer $50 \%$ igen, aber der anfängliche Blutdruckabfall tritt fast gar nicht ein, wie im letzteren Falle. Eine $10 \%$ ige, zu ca. $10 \mathrm{ccm}$ gegeben, wirkt fast gar nicht blutdruckverändernd.

Aus diesen Resultaten ist zu erkennen, dass bei stomachaler Verabreichung von Alkohol der Blutdruck ab und zu plötzlich, aber nachher 
allmählich sinkt, dass die Pulszahl zwar mit der Blutdrucksenkung sich ändert, aber wenn diese graduell gering ist, sich vermehrt und bei hochgradiger Blutdrucksenkung sich vermindert. Die Fälle, bei welchen Alkohol in kleiner Menge gegeben, allmählich geringe Blutdrucksenkung und Pulszunahme bewirkt, stehen mit denen, in welchen Menschen verdünnter Alkohol gegeben wird, in sehr gutem Einklang.

Einige sagen zwar, dass bei Einführung von Alkohol in den Magen anfängliche Blutdrucksteigerung vorkommt, was aber in meinen Fällen niemals beobachtet werden konnte. Dürfte nicht, da, wie schon erwähnt, die Reizung der Mundschleimhaut blutdrucksteigernd wirkt, die von ihnen beobachtete Blutdruckzunahme von unvorsichtiger Applikation her rühren? Unabhängig davon, ob diese vorläufige Blutdrucksenkung erfolgt, oder nicht, tritt schliesslich allmählich Blutdruckernierdrigung auf. Dies stimmt mit den Berichten einer grossen Anzahl von Forsehern überein und steht ausser allem Zweifel. Nur Dixon hat Blutdrucksteigerung nachgewiesen ; worauf dies beruht, ist nicht zu erklären. Die Untersuchung der von ihm zum Belege angegebenen Kurven lässt erkennen, dass der Blutdruck gleich nach der Applikation ansteigt, und lässt Zweifel daran aufkommen, ob die Wirkung in der Tat eine resorptive ist oder nicht. Beruht seine Blutdruckerhöhung nicht auf anderen Ursachen, wie z.B. nachlässiger Applikation ? Einige sagen, dass die Pulszahl zu-, und andere, dass sie abnimmt; dieser Unterschied hängt von der Menge $a b$, und die Pulszahl wird bei leicht blutdruckherabsetzender Menge vermehrt und bei erheblich blutdrucksenkender vermindert.

Da anfängliche Blutdruckerniedrigung keine konstante Erscheinung ist, ist sie schwer zu analysieren, aber jedenfalls ist sie von der Konzentration des Alkohols abhängig, jedoch nicht von seiner absoluten Menge; sie stellt sich sofort nach der Applikation ein und verschwindet in kurzer Zeit, woraus zu ersehen ist, dass der konzentrierte Alkohol höchst wahrscheinlich die sensiblen Nerven der Magenwand reizt und dadurch den Reflex auslöst. Die darnach auftretende Blutdrucksenkung zeigt sich nach mehreren Minuten, wird allmählich deutlicher und verschwindet ebenfalls allmählich; ferner ist sie nicht von der Konzentration des Alkohols sondern von seiner absoluten Menge abhängig, wonach sie also mit Recht als resorptive Wirkung anzusehen ist. Ist dies nun der Fall, auf welche Weise wirkt dann Alkohol blutdrucksenkend ? Bei geringer Blutdruckerniedrigung nimmt die Pulszahl zu, sodass diese Erniedrigung wahrscheinlich nicht durch verminderte Arbeitsleistung des Herzens, sondern durch Vasodilatation bedingt ist. Die Pulszunahme rührt wohl vom Nachlassen 
des Vagustonus infolge herabgesetzten Blutdruckes her. Daraus, dass bei erheblicher Blutdruckabnahme zugleich der Puls verlangsamt wiird, ist wohl mit Recht zu schliessen, erstere sei dadurch herbeigeführt dass an der Gefässerweiterung die verminderte Arbeitsleistung des Herzens beteiligt ist. Dass diese Vermutung den Tatsachen entspricht, erhellt daraus, dass beim Onkometerversuch an beiderseits vagotomierten Tieren der Blutdruckabfall Veränderungen des Bein- und Darmovolums aufweist. Fig. 11 zeigt ein Beispiel dafür.

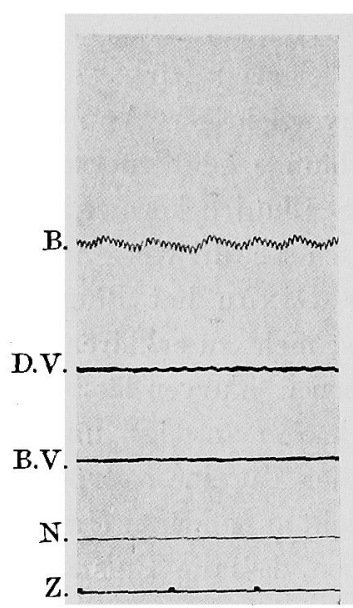

(1)

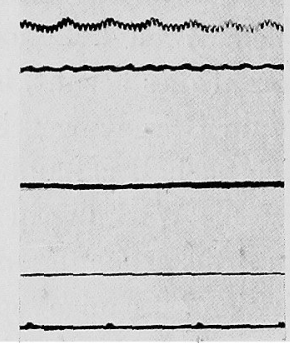

(2)
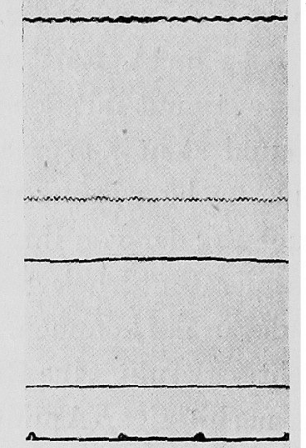

(3)

Fig. 11.

Kaninchen $1,9 \mathrm{~kg}$. Urethannarkose.

Beide Vagi durchgeschnitten.

$20 \mathrm{ccm} 50 \%$ iger Alkohollösung in den Magen.

(1) Vor der Applikation;

(2) 20 Min. nach der Applikation;

(3) 60 Min. nach der Applikation.

B. $=$ Blutdruck ; D.V. = Darmvolum; B.V. $=$ Beinvolum ;

N. = Nullinie ; Z $=$ Zeit in 5 Sek.

Darm- und Beinvolum zeigen mit der Blutdruckerniedrigung Vergrösserung, welche graduell zusammen mit letzterer zunimmt. Die Pulszahl sinkt, ohne sich in Anfang zu vermehren, mit der Blutdrucksenkung und zwar desto mehr, je bedeutender letztere ist. Nämlích beim Sinken von $104 \mathrm{~mm} \mathrm{Hg}$ Blutdruck auf $77 \mathrm{~mm} \mathrm{Hg}$ vermindert sích die Pulszahl von 210 pro Min. auf 204 und bei der Abnahme des ersteren auf $54 \mathrm{~mm}$ Hg sinkt letztere auf 163 .

Daraus geht hervor, dass Alkohol zwar Vasodilatation, Abnahme der Herzfrequenz und Herabsetzung des Blutdrucks hervorruft, aber zngleich mit letzterer den Vagustonus abschwächt, so dass die Herzschläge vermehrt und bis zu einem gewissen Grade ausgeglichen werden. Also 
nimmt der Puls bei schwacher Alkoholwirkung zu, aber bei hochgradiger wird das Herz äusserst stark angegriffen so dass die kompensatorische Vermehrung als nicht stattfindend angesehen werden muss. Wie erweitern sich nun die Gefässe? Die lähmende Wirkung des Alkohols auf das vasomotorische Zentrum ist allbekannt. Dass ferner verdünnter Weingeist auf die isolierten Organe der Warmblüter vasodilatatorisch wirkt, ist auch nach den Experimenten von Dixon, ${ }^{11}$ Mori, ${ }^{12)}$ Gatel u. Mennicke, ${ }^{13)}$. Weber ${ }^{14)}$ und anderen Forschern sicher. Worauf beruht nun in diesem Falle die Vasodilatation? Aus der Tatsache, dass bei einem Tiere mit durchschnittenem Halsmarke bei Einführung von $4 \mathrm{ccm}$ $50 \%$ iger Alkohollösung pro $\mathrm{kg}$ Körpergewicht in den Magen keine erhebliche Wirkung auftritt, wohl aber bei stomachaler Verabreichung von $10 \mathrm{ccm}$ derselben Alkohollösung pro kg Körpergewicht der Blutdruck sinkt, ist zu schliessen, dass durch eine kleine Menge Alkohol bewirkte Blutdruckabnahme hauptsächlich auf Lähmung des Zentrums beruht, aber die durch eine grosse Menge bedingte wohl noch mit durch Beteiligung der Gefässlähmung verursacht wird. Wie entsteht nun weiter die Abnahme der Arbeitsleistung des Herzens? Dixon ${ }^{11)}$ und einige andere Autoren teilen mit, dass Alkohol auf isolierte Warmblüterherzen erregend wirkt, während $\mathrm{Kuno},{ }^{15)} \mathrm{Fischer},{ }^{16)} \mathrm{Ch}$ iston $\mathrm{i}^{17)}$ u. a. durch vorsichtige Untersuchungen Dixonsche Ergebnisse in Abrede gestellt und gefunden haben, dass Weingeist in verdünnter Lösung wirkungslos ist und in einer Konzentration, in welcher die Wirkung zum Vorschein kommt, lähmend zu wirken scheint. Meine Versuchsergebnisse stehen auch mit denen der letzteren Autoren im Einklang. Die Pulsabnahme bei stomachaler Verabreichung des Alkohols rührt wahrscheinlich von seiner direkt lähmenden Wirkung auf das Herz her.

\section{c. Applikation in den Darm.}

Die Veränderungen des Blutdruckes und der Pulsfrequenz bei Applikation des Alkohols in den Darm oder das Rektum stimmen mit denen bei seiner stomachalen Verabreichung fast ganz überein.

12) Mori, zit. nach Meyer-Gottlieb, Die experimentelle Pharmakologie, Berlin $1923,281$.

13) Gatel u. Mennicke, Zeitsch. f. d. ges. exp. Med., 1923, 32, 281.

14) Weber, Arch. f. Anat. u. Physiolog., 1907, 76, 348.

15) Ku no, Kioto-Igaku-Zasshi, 1910, 7, 20 (jap.); Arch. internat. de pharmacodyn. et de thérap., 1912, 22, 355.

16) Fischer, Arch. f. exp. Path. u. Pharm., 1898, 4l, 174.

17) Chistoni, Arch. inter. de physiolg., 1914, 14, 201. 


\section{d. Subkutane Applikation.}

Wird einem schwach urethanisierten Kaninchen $10 \mathrm{ccm} 10 \%$ iger Alkohollösung pro $\mathrm{kg}$ Körpergewicht subkutan verabreicht, so beginnt nach mehreren Minuten Blutdruckabfall, welcher allmählich deutlicher wird und nach 20-30 Minuten 5-15 mm Hg beträgt, dann allmählich zurückgeht, bis er in ca. 60 Minuten wieder die Norm erreicht. Die Pulszahl nimmt, im Gegensatz zum Blutdruck, erst allmählich zu, dann allmählich ab, bis sie wieder normal wird. Auch bei Applikation von 2 ccm 50\%iger Alkohollösung pro $\mathrm{kg}$ Körpergewicht erfolgen analoge Veränderungen. Nach der Injektion sinkt der Blutdruck sehr selten sofort. Dieser wird immer niedriger, wenn man von $50 \%$ igem Alkohol eine grosse Menge, z. B. $10 \mathrm{ccm}$ pro kg Körpergewicht, gibt, und wird in 30 Minuten halb so hoch wie der normale Druck, und es zeigt sich auch Pulsverlangsamung. Diese Erscheinungen zeigen zwar Neigung, sich allmählich zu restituieren, aber innerhalb einer Stunde finden keine Veränderungen statt.

Diese Symptome sind denen bei stomachaler Applikation ganz gleich. Von beiden Blutdrucksenkungen ist der selten auftretende, anfängliche wohl reflektorischer Natur und der regelmässig allmählich zum Vorschein kommende als resorptive Wirkung anzusehen.

\section{e. Intravenöse Applikation.}

Zahlreiche Forscher haben sich mit den Blutdruckveränderungen bei intravenöser Applikation von Alkohol beschäftigt. Dass letzterer in grosser Menge blutdruckherabsetzend wirkt, darüber sind sich alle einig, aber über seinen Einfluss auf den Blutdruck bei Verabreichung einer kleinen Menge sind die Ansichten der Forscher geteilt. Zi mmerberg, Bock, ${ }^{18}$ Pässler, ${ }^{19}$ Brocks ${ }^{97}$ u. a. haben nämlich Drucksenkung gefunden, während Kochmann, ${ }^{20)}$ Dixon, ${ }^{11)}$ Hascovec, ${ }^{21)}$ Nakagawa, ${ }^{22)}$ u. a. das Gegenteil feststellen. $\mathrm{Knno} \mathrm{o}^{10)}$ hat auch vor der Drucksenkung eine vorübergehende leichte Drucksteigerung beobachtet, welche aber nach ihm von der eigentlichen Alkoholwirkung herrührt. Warum die Ansichten der Autoren so stark auseinandergehen, ist zwar nicht klar,

18) Bock, Arch. f. exp. Path. n. Pharm., 1898, 41, 174.

19) Pässler, Deutsch. Arch. f. klin. Med., 1899, 64, 725.

20) Ko chmann, Arch. inter. de Pharm. et de Thérap., 1904, 13, 329.

21) Hasco vec, Wiener med. Wochenschrift, 1909, 59, 459.

22) Nakagaw a, Tohoku Journ. of Exp. Med, 1921, 5, 190. 
aber aus ihren Mitteilungen lässt sich so weit schliessen dass es nicht mit der Verschiedenheit ihrer Versuchstiere in Beziehung steht. Deshalb habe ich an Kaninchen Versuche angestellt.

Führt man urethanisierten Kaninchen $10 \mathrm{ccm} 5 \%$ iger Alkohollösung pro $\mathrm{kg}$ Körpergewicht sehr langsam in die Ohrvene ein, so zeigt der Blutdruck keine Veränderung oder eine geringe Erhöhung, welch letztere sehr allmählich erfolgt, in 5 Minuten nur 2-3 mm $\mathrm{Hg}$ beträgt und in der Regel in 10 Minuten auf die Norm zurückgebt. Bei intravenöser Applikation von $1 \mathrm{ccm}$ 50\%iger Alkohollösung zeigt der Blutdruck, auch bei ziemlich langsamer Injektion, manchmal Neigung zu vorübergehender Erniedrigung, dann geht er regelmässig in die Höhe, welche Erhöhung jedoch individuell verschieden, meistens leichten Grades ist und ziemlich lange, 30-60 Minuten oder noch länger, dauert. Fig. 12 veranschaulicht das.

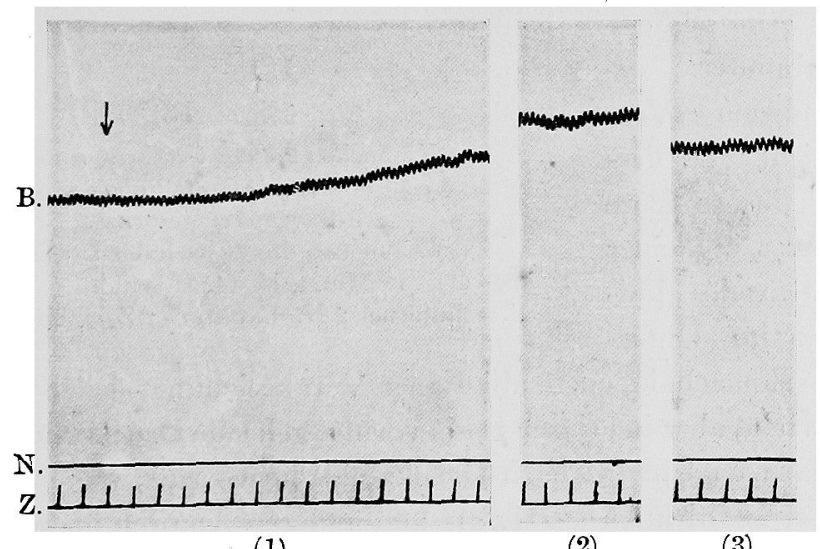

(1)

(2)

(3)

Fig. 12.

Kaninchen $1,8 \mathrm{~kg}$. Urethannarkose. $1 \mathrm{ccm} 50 \%$ iger Alkohollösung intravenös eingespritzt.

Der Pfeil markiert den Beginn der Injektion.

(1) Vor und direkt nach der Injektion;

(2) 30 Min. nach der Injektion;

(3) $60 \mathrm{Min}$. nach der Injektion.

B. $=$ Blutdruck ; N. = Nulllinie ; Z. $=$ Zeit in 5 Sek.

Der Blutdruck, welcher vor der Applikation $82 \mathrm{~mm} \mathrm{Hg}$ betrug, stieg 1 Min. nach der Verabreichung von $1 \mathrm{ccm} 50 \%$ iger Alkohollösung (pro kg) auf $92 \mathrm{~mm} \mathrm{Hg}$, in 30 Minuten auf $106 \mathrm{~mm} \mathrm{Hg}$ und zeigte nach 60 Minuten, als er schon mehr oder weniger wieder zurückgegangen war, noch immer $98 \mathrm{~mm}$.

Beibringung von $5 \mathrm{ccm}$ 50\%iger Lösung bewirkt, dass der Druck, nachdem er prompt gesunken war nach und nach wieder ansteigt, dann 
allmählich heruntergeht, bis er subnorm tief wird. Fig. 13 zeigt ein Beispiel davon.

Der Druck, welcher vor der Applikation $112 \mathrm{~mm} \mathbf{H g}$ hoch war, wurde unmittelbar nach ihr auf $90 \mathrm{~mm} \mathrm{Hg}$ erniedrigt, nach 2 Minuten auf 122 mmi $\mathrm{Hg}$ gehoben und nach 10 Min. auf $76 \mathrm{~mm} \mathrm{Hg}$ gesenkt.

Gibt man ca. $10 \mathrm{ccm}$ $50 \%$ iger Alkohollösung, so sinkt der Druck sofort, zeigt danach Neigung zum Anstieg, erreicht aber die Normalhöhe nicht und fällt schliesslich sehr hinunter.

Aus obigen Versuchen ersieht man, dass Alkohol, insbesondere konzentrierter, in kleiner Menge intravenös injiziert, ganz im Unter-

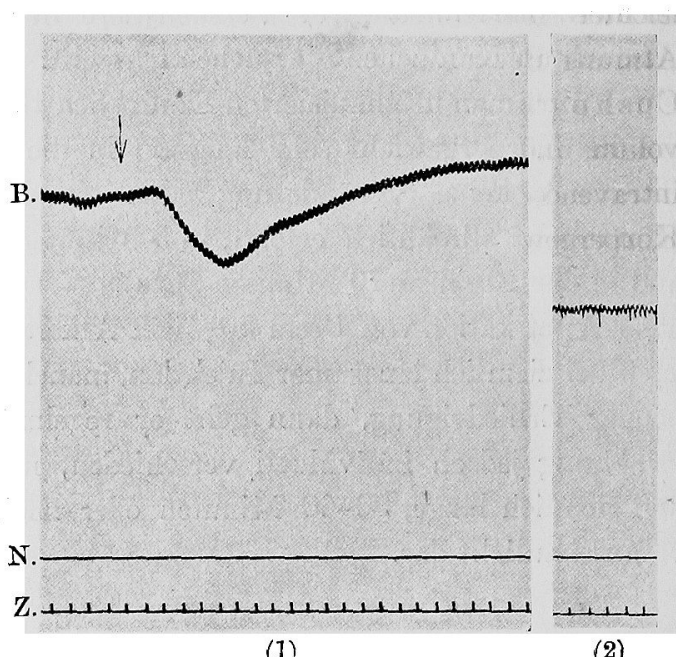

(1)

Fig. 13.

Kaninchen 2,1 kg. Urethannarkose. 5 ccm 50\% iger Alkohollösung pro kg intravenös eingespritzt.

(1) Vor und direkt nach der Injektion;

(2) 10 Min. nach der Injektion.

B. $=$ Blutdruck $; N_{.}=$Nulllinie $; Z .=Z$ Zeit in 5 Sek.

schiede von stomachaler oder subkutaner Verabreichung, sicher blutdrucksteigernd wirkt, aber in grosser Dosis vorübergehende Druckerhöhung oder Neigung dazu zeigt und danach Druckabfall hervorruft, was mit den Resultaten von Kochmann, Dixon und anderen Autoren übereinstimmt. Dass aber die anderen Forscher den Druckanstieg nicht beobachten konnten, beruht meiner Meinung nach darauf, dass sie die Lösung nicht in geeigneter Konzentration und Menge gebraucht haben. Wie entsteht denn die Blutdrucksteigerung durch eine kleine Menge Alkohol ? Kochmann ist der Ansicht, sie rühre davon her, dass trotz aktiver Erweiterung der peripheren Gefässe doch die des Splanchnicusgebietes sich so stark zusammenziehen, dass dadurch erstere überwunden wird, aber Dixon, Bachem ${ }^{23)}$ u. a. wollen die erwähnte Blutdruckerhöhung der gesteigerten Arbeitsleistung des Herzens zuschreiben.

Einige Autoren behaupten, dass man bei der Untersuchung des Einflusses der intravenösen Injektion von Alkohol Tiere nicht betäuben

23) Bachem, Arch. intern. de Pharm. et de Thérap., 1905, 14, 437. 
darf, aber nach meinen Versuchen steigt der Blutdruck auch unter leichter Narkose deutlich an. Dabei eröffnete ich unter künstlicher Atmung Brust und Bauch, dann registrierte ich zu gleicher Zeit mittelst Cushny's Myocardiograph die Herzschläge, onkometrisch das Darmvolum und mittelst $\mathrm{Hg}$-Manometer den Carotisdruck. Bei langsamer intravenöser Applikation von $1 \mathrm{ccm} 50 \%$ iger Alkohollösung pro $\mathrm{kg}$ Körpergewicht nimmt der Blutdruck, wie aus Fig. 14 ersichtlich, zu und

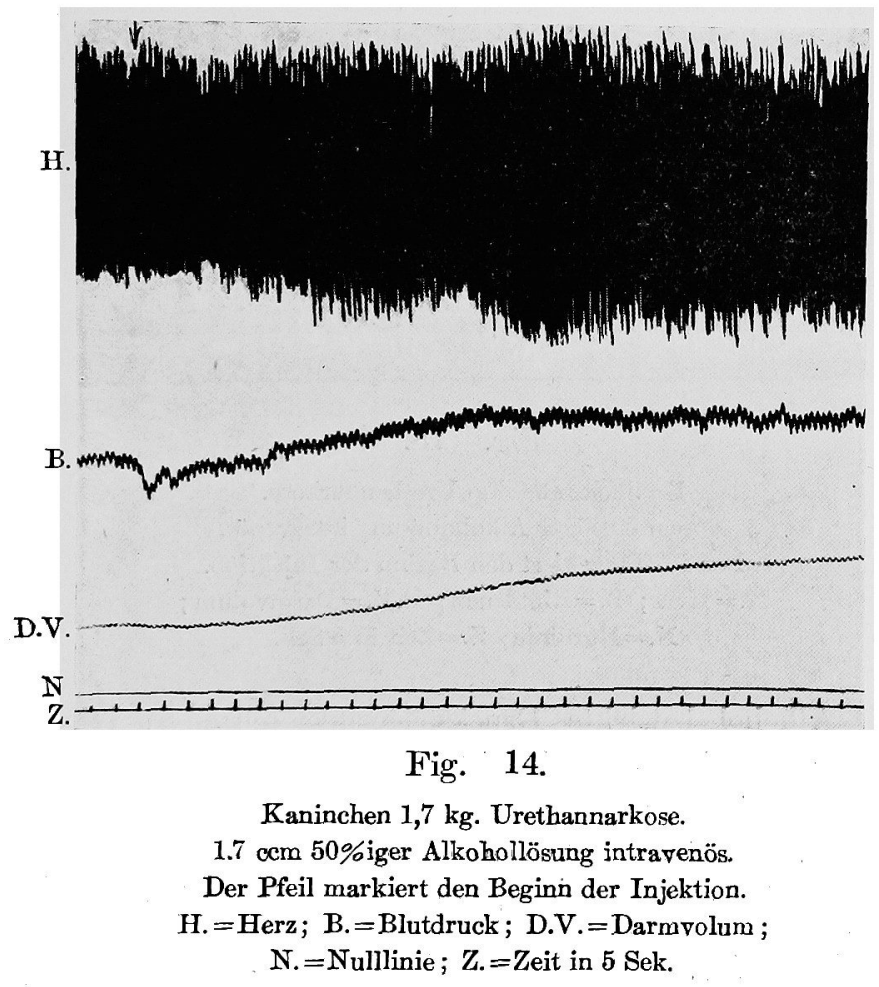

damit auch die Amplitude der Herzschläge und das Darmvolum. Die Blutdrucksteigerung kommt als Folge der Zunahme der Arbeitsleistung des Herzens zustande, und die Zunahme des Darmvolums durch die Druckerhöhung. Aber bei Darreichung einer grossen Menge, z.B. von 5 cem 50\% iger Lösung, ist das Verhalten anders. Wie Fig. 15 zeigt, wird zwar der Blutdruck gesteigert, aber die Herzschläge in der Amplitude vielmehr verkleinert und auch das Darmvolum vermindert. Dass Druckanstieg trotz solcher Abnahme der Arbeitsleistung auftritt, muss als hauptsächlich durch Kontraktion der Darmgetässe bedingt angesehen werden. 


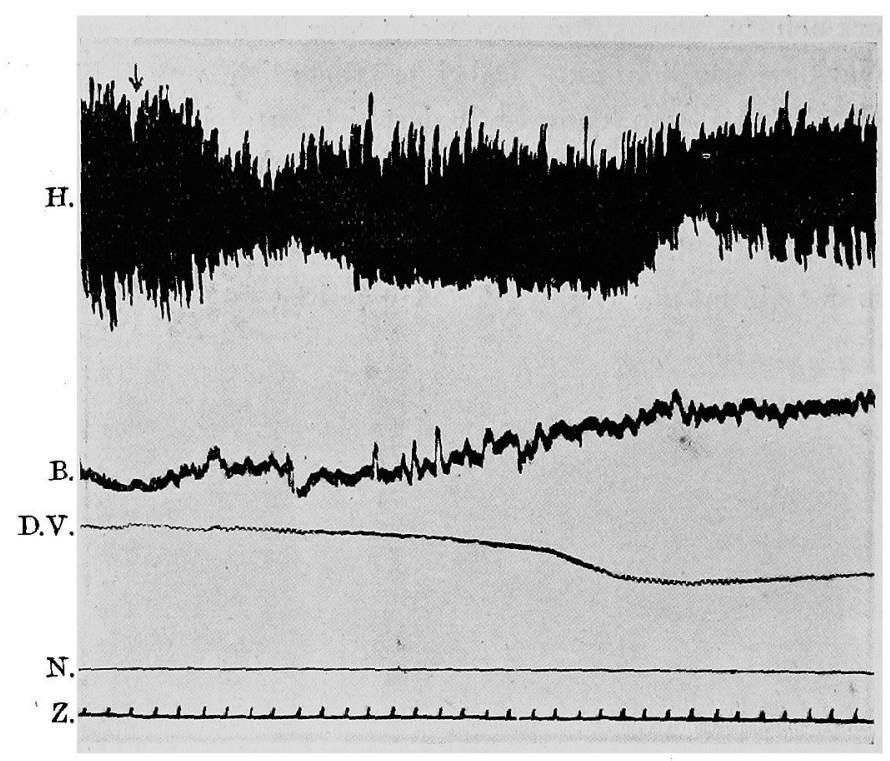

Fig. 15.

Kaninchen 2,0 kg. Urethannarkose.

$10 \mathrm{ccm} 50 \%$ iger Alkohollösung intravenös.

Der Pfeil markiert den Beginn der Injektion.

H. =Herz; B. =Blutdruck; D.V. = Darmvolum;

$\mathrm{N} .=$ Nulllinie $; \mathrm{Z} .=$ Zeit in 5 Sek.

Die durch Alkohol bewirkte Drucksteigerung schreiben Dixon und Bachem der vermehrten Arbeitsleistung des Herzens und Kochmann der Vasokonstriktion zu ; dieser Unterschied ist durch die Menge des Alkohols bedingt. Da diese Veränderungen auch bei Tieren, denen das Halsmark durchschnitten ist, eintreten, besteht kein Zweifel, dass Weingeist peripherisch wirkt, in kleiner Menge die Arbeitsleistung des Herzens vermehrt, in grosser die Gefässe zur Kontraktion und dadurch den Blutdruck zum Steigen bringt. Aber weil Alkohol, wie oben erwähnt, in verschiedenen Mengen stomachal oder subkutan beigebracht, niemals blutdruckerhöhend wirkt, ist es zweifelhaft ob bei intravenöser Verabreichung von Alkohol die Blutdrucksteigerung tatsächlich als ihre eigentliche resorptive Wirkung anzusehen ist oder nicht. Nach Dixon, ${ }^{11)}$ Gatel und Mennick ${ }^{13)}$ und anderen Autoren wirkt Alkohol in verdünnter Lösung auf die isolierten Gefässe erweiternd und in konzentrierter zusammenziehend. Dann wäre es möglich, dass letztere in grosser Dosis intravenös appliziert, mag sie schliesslich auch durch Blut verdünnt werden, doch eine Zeit lang 
konzentriert bleiben müsste und dadurch Gefässkontraktion hervorriefe. Weiter teilen Loeb, ${ }^{24)}$ Dixon, ${ }^{11)}$ Brandini ${ }^{25)}$ u. a. mit, dass Einfluss verdünnten Alkohols auf das isolierte Herz ein günstiger ist, was aber

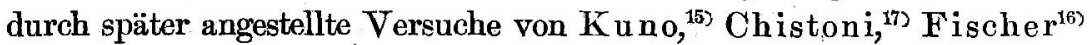
u. a. nicht nur nicht bestätigt, sondern im Gegenteil immer verneint wurde. Ist dies der Fall, auf welche Weise vergrössert sich dann die Amplitude der Herzschläge bei Applikation konzentrierten Alkohols in kleiner Menge? Dass dies nicht zur Zeit, wo letzterer vom Verdaungskanal oder subkutanen Gewebe in die Blutbahn eindringt, zustande kommt und dass der Grad der Blutdrucksteigerung nicht von der absoluten Menge des Alkohols, sondern von seiner Konzentration abhängt, lässt erkennen, dass die günstige Wirkung auf das Herz in Beziehung zur Vermischung des konzentrierten Alkohols mit dem Blut stehen muss. Auch aus der Tatsache, dass nach Cushny und $\mathrm{Gunn}^{26)}$ aus Kaninchen gewonnenes Serum oder Plasma auf ihr isoliertes Herz erregend wirkt, lässt vermuten, dass die Veränderung des Blutes eine günstige Wirkung auf das Herz entfalten kann. Ich habe ein isoliertes Kanin-

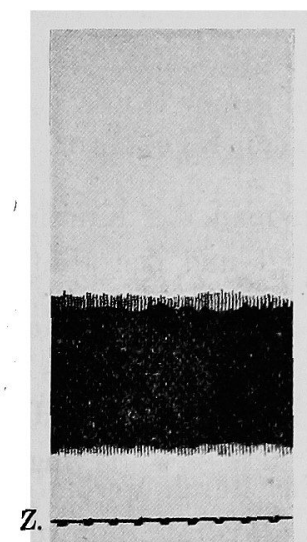

(1)

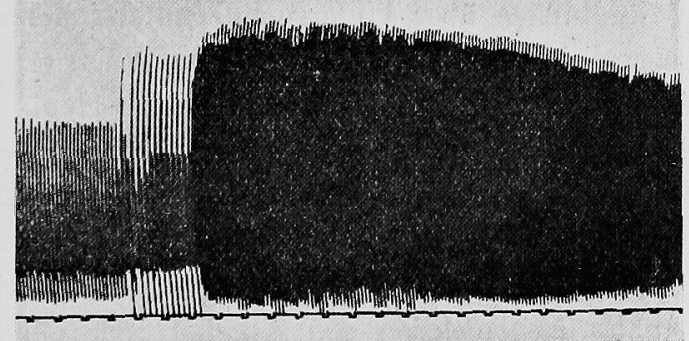

(2)

Fig. 16.

Isoliertes Kaninchenherz, unter Ringer-Blutmischung.

(1) Normaler Zustand.

(2) 2 Min. nach d. Umschaltung auf Alkohol-Ringer-Blutmischung. (1 ccm 50\%iger Alkohollösung in $100 \mathrm{ccm}$ Blut.)

$$
\text { Z. = Zeit in } 4 \text { Sek. }
$$

24) Loeb, Arch. f. exp. Path. u. Pharm., 1905, 52, 459.

25) Brandini, zit. nach Goldsch midt, Zentralblatt $f$. Physiolog., 1914, 14, 201.

26) Cushny u. Gunn, Jour. of Pharm. and Exp. Therap., 1913-1914, 5, 3. 
chenherz von mit Ringerlösung ums zehnfache verdünntem Kaninchenserum durchströmen lassen. Danach wurde es auf dieselbe Flüssigkeit mit $1 \mathrm{ccm} 50 \%$ iger Alkohollösung umgeschaltet, wodurch aber die Herzschläge gar keine Veränderung erfuhren. Wurde aber letztere Lösung mit solcher vertauscht, bei der man zu $100 \mathrm{cem}$ Serum $1 \mathrm{cem}$ 50\%iger Alkohollösung hinzusetzt, das ganze schüttelt, dann mit 11 Ringerlösung versetzt, dann zeigte das Herz, wie aus Fig. 16 ersichtlich, in der Amplitude vergrösserte Pulsation und vermehrten Rhythmus. Daraus folgt, dass die Blutdrucksteigerung bei intravenöser $Z$ ufuhr von Alkohol davon herrührt, dass dieser die Beschaffenheit des Serums verändert und dadurch kardiotonisch wirkt, und dass sie nicht durch Alkohol selbst hervorgerufen wird.

Wie dem auch sei, die Wirkungen des Alkohols auf den Blutdruck sind bei innerlicher Darreichung und bei intravenöser Injektion ganz verschieden voneinander. Klinisch werden alkoholische Getränke immer per os und nicht intravenös verabreicht. Wenn man also auch bei intravenöser Applikation von Alkohol den Blutdruck hat ansteigen sehen, so ist es doch ganz sinnlos, danach die klinischen Erfolge zu beurteilen.

\section{Einfluss des Alkohols auf den gestörten Kreislauf.}

Mitteilungen über Untersuchungen, bei denen man die Kreislaufstörungen bei Tieren auf irgend welche Weise erzeugt und den Einfluss des Alkohols auf sie erforscht hat, sind sehr selten. Pässle ${ }^{27)}$ hat einem durch eine Infektion vasomotorisch gestörten Tiere Alkohol gegeben und dadurch den Kreislauf zuweilen sich haben bessern gesehen; das aber ist der einzige bis jetzt erstattete Bericht.

Ich habe einem Kaninchen, bei welchem vorher durch Verblutung oder subkutane Injektion yon Alkohol oder Chloralhydrat Blutdrucksenkung hervorgerufen war, Alkohol nach verchiedenen Methoden, z. B. in den Mund, stomachal, subkutan oder intravenös, gegeben und den Einfluss auf den Blutdruck untersucht. Das ergab, dass ersterer, wenn auch in der Stärke von dem beim normalen Kreislauf verschieden, qualitativ gleich ist. Aber bei erheblichem Blutdruckabfall wirkt Alkohol, in den Mund beigebracht, nicht deutlich drucksteigernd.

27) Pässler, Dèut. Arch. f. klin. Med., 1899, 64, 725. 


\section{Schluss.}

1. Bei Applikation konzentrierten Alkohols auf die Mundschleimhaut des Menschen und Kaninchens stellen sich sofort Blutdruckanstieg und Pulsabnahme ein, welche aber nur mehrere Minuten danern. Ersterer wird tierexperimentell dadurch herbeigeführt, dass Weingeist sensible Nerven der Mundschleimhaut reizt und dadurch reflektorisch vasokonstriktorisch wirkt. Pulsverminderung wịrd durch die Erhöhung des Vagustonus infolge gesteigerten Blutdrucks zustande gebracht.

2. Gibt man einem Menschen innerlich konzentrierten Alkohol, dann treten sofort die oben erwähnten Veränderungen auf, aber nur allmählich Blutdruckerniedrigung und Pulszunahme. Führt man einem Tiere unter Schonung der Mundschleimhaut Alkohol in den Magen ein, so wird der Blutdruck, statt zunächst in die Höhe zu gehen, erniedrigt und die Pulsfrequenz vermehrt. Die zuerst eintretende Drucksteigerung bei Menschen ist reflektorischer Natur, hervorgerufen durch Reizung von der Mundschleimhaut aus, aber die sich allmählich geltend machende Drucksenkung ist wohl eine resorptive Wirkung. Diese Druckabnahme entsteht durch die erregbarkeitherabsetzende Wirkung des Alkohols auf das vasomotorische Zentrum und die Pulszunahme wohl durch Nachlassen des Vagustonus. Ist die verabreichte Menge eine ziemlich grosse, so nehmen Blutdruck und Pulsfrequenz noch mehr ab, weshalb ausser der oben geschilderten Vasodilatation auch noch die herabgesetzte Arbeitsleistung des Herzens als am Druckabfall beteiligt angesehen werden muss.

3. Falls Alkohol Tieren in den Darm oder subkutan gegeben wird, zeigen sich am Kreislauf dieselben Veränderungen wie bei stomachaler Applikation.

4. Bei intravenöser Injektion konzentrierten Alkohols bei Tieren stellt sich Blutdrucksteigerung ein, welche aber nicht auf seiner resorptiven Wirkung beruht, sondern darauf, dass konzentrierter Weingeist durch seine Wirkung auf die Blutbeschaffenheit das Herz anregt und in grosser Menge Vasokonstriktion herbeiführt, mag er auch aufs Herz schädigend wirken.

5. Die erwähnten Wirkungen auf Kaninchen machen sich auch bei denen mit gestörtem Kreislauf geltend, nur mit graduellen Unterschieden.

6. Die günstige Wirkung des Alkohols auf den Kreislanf rührt wohl, da er in der Klinik per os gegeben wird, von der reflektorischen 
Vasokonstriktion her.

7. Viele Forscher haben bei Fintührung des Alkohols in die Blutbahn der Tiere Blutdruckanstieg beobachtet und haben versucht, dadurch die günstige therapentische Wirkung zu erklären, aber sie ist von der resorptiven Wirkung, die nach oraler Verabreichung eintritt, ganz verschieden.

8. Finige Forscher behaupten, dass nach ihren Untersuchungsergebnissen verdünnter Weingeist bei intravenöser Applikation blutdrucksenkend wirkt und keine günstige therapeutische Wirkung entfaltet, was aber auch nicht richtig ist. 